\title{
Bone and collagen turnover during treatment with inhaled dry powder budesonide and beclomethasone dipropionate
}

\author{
N H Birkebæk, G Esberg, K Andersen, O Wolthers, C Hassager
}

\begin{abstract}
Objective-To assess bone and collagen turnover in asthmatic children treated with dry powder budesonide from the Turbuhaler and dry powder beclomethasone dipropionate from the Diskhaler in a dose of $800 \mu \mathrm{g} / \mathrm{day}$.
\end{abstract}

Subjects-Thirteen prepubertal children with asthma.

Design-Open crossover study with two treatment periods and treatment free run-in and wash-out periods. All periods were of two weeks' duration. At day 14 in each period blood samples were taken for assessment of serum osteocalcin, the carboxyterminal propeptide of type I collagen (PICP), and the aminoterminal propeptide of type III collagen (PIIINP). At the same time urine was collected for assessment of creatinine corrected pyridinoline (uPYR/cr) and deoxypyridinoline (udPYR/cr) crosslinks.

Results-Osteocalcin concentrations were not influenced by any of the treatments. During budesonide treatment mean (SEM) PICP was reduced by $18 \%(8 \%)(p=0 \cdot 03)$, PIINP by $24 \%(3 \%)(p=0 \cdot 0002)$, uPYR/cr by $16 \%(6 \%)(p=0.03)$, and udPYR/cr by $21 \%(13 \%) \quad(p=0 \cdot 12)$. During treatment with beclomethasone dipropionate mean (SEM) PICP was reduced by $20 \%(6 \%)$ $(p=0 \cdot 01)$, PIIINP by $36 \%(3 \%)(p=0 \cdot 0002)$, UPYR/cr by $18 \%(4 \%) \quad(p=0.004)$, and udPYR by $13 \%(5 \%)(p=0 \cdot 02)$. The suppressive effect of beclomethasone dipropionate on PIIINP was more marked than that of budesonide $(p=0 \cdot 001)$.

Conclusion-Treatment with dry powder budesonide and beclomethasone dipropionate $800 \mu \mathrm{g} / \mathrm{day}$ is associated with suppression of bone and collagen turnover. The suppression seems to be more marked during treatment with beclomethasone dipropionate. Long term effects and effects of lower doses of budesonide and beclomethasone dipropionate on bone and collagen markers needs further study.

(Arch Dis Child 1995; 73: 524-527)

Keywords: budesonide, beclomethasone dipropionate, procollagen peptides, pyridinoline crosslinks.

We recently evaluated some new markers of bone and collagen turnover as measures of systemic effects on children treated with glucocorticosteroids. Serum concentrations of osteocalcin, a marker of bone formation, were depressed during treatment with low doses of oral prednisolone but not during treatment with inhaled budesonide 200 and $800 \mu \mathrm{g}$ from a pressurised metered dose inhaler with a spacer. ${ }^{1}$ The aminoterminal propeptide of type III procollagen (PIIINP), a serum marker of type III collagen synthe sis, and the carboxyterminal propeptide of type I procollagen (PICP), a marker of type I collagen synthesis, were suppressed during treatment with prednisolone. ${ }^{2}$ These findings suggest that valuable information about glucocorticosteroid induced effects on bone and collagen turnover may be obtained from studies of these serum markers.

Treatment with inhaled glucocorticosteroids using dry powder inhalers are increasingly preferred due to concern about possible adverse effects of the Freon driven metered dose inhalers on the environment. Budesonide delivered from the Turbuhaler and beclomethasone dipropionate delivered from the Diskhaler are widely used dry powder delivery devices. The aim of the present study was to evaluate whether budesonide $800 \mu \mathrm{g} /$ day delivered from the Turbuhaler and beclomethasone dipropionate $800 \mu \mathrm{g} /$ day delivered from the Diskhaler influence serum and urinary markers of bone and collagen turnover in children.

\section{Subjects and methods}

Twelve prepubertal boys and four prepubertal girls were studied. All suffered from mild asthma and needed treatment only with inhaled $\beta_{2}$ stimulants at the time of the study. Mean (range) age was 8.7 years (6-11.5 years), and mean body surface area was $1.0 \mathrm{~m}^{2}$ $\left(0 \cdot 78-1 \cdot 20 \mathrm{~m}^{2}\right)$.

The study was an open crossover trial with periods of 14 days. In period 1 (run-in) and 3 (wash-out) no treatment was given. In periods 2 and 4 the children took dry powder budesonide from the Turbuhaler or dry powder beclomethasone dipropionate from the Diskhaler in a dose of $800 \mu \mathrm{g} /$ day. Treatment order was allocated by means of a computerised randomisation scheme prepared in balanced blocks. The inhalations were taken twice daily at $8 \mathrm{am}$ and $8 \mathrm{pm}$ as two actuations of $200 \mu \mathrm{g}$. The children were carefully instructed in inhalation techniques. They were asked to rinse their mouth after the inhalations. As a measure of compliance, the number of delivered inhalations taken by each patient was counted. If compliance was less than $80 \%$ the patient was excluded from the study. 
Forced expiratory volume in one second was measured with a dry wedge spirometer (Vitalograph) at each visit. Peak expiratory flow was measured at home in the morning and in the evening with a mini-Wright peak flow meter. To avoid any influence of changes in pulmonary function on the markers of bone and collagen turnover children showing more than $15 \%$ variation in pulmonary function between the various periods or more than $25 \%$ day to day variation in peak flow were withdrawn from the study.

Samples of blood and urine were taken at the end of each period between $2 \mathrm{pm}$ and 3 pm. The children were instructed to empty their bladder at roughly $11 \mathrm{am}$ and to discard the urine. Afterwards they were asked not to urinate again until urine sampling at 2-3 pm. The blood was centrifuged within one hour after sampling. Serum and urine samples were stored at $-80^{\circ} \mathrm{C}$ and batch assayed at completion of the study.

\section{SERUM AND URINE ANALYSIS}

The plasma concentration of osteocalcin was measured by a radioimmunoassay. ${ }^{3}$ Antiserum was raised in rabbits immunised with purified calf osteocalcin, and homogenous calf osteocalcin was used for standard and tracer. The intra-assay and interassay variations were less than $10 \%$. The serum concentration of PICP was determined by a radioimmunoassay recently developed. ${ }^{4}$ The assay is based on PICP purified from the cell culture medium of human fetal fibroblasts; this PICP is cleaved as in vivo from collagen. The assay uses polyclonal rabbit antibodies. The intra-assay and interassay variations were less than $2 \%$ and $4 \%$, respectively. The serum concentration of intact and high molecular weight PIINN was determined by a commercial available radioimmunoassay (PIINP RIA Kit, Farmos Diagnostica, Oulunsalo, Finland). ${ }^{5}$ The assay uses polyclonal rabbit antibodies. The antigen used is purified human PIINP. The intraassay and interassay variations were less than $3 \%$ and 5\%, respectively. The urinary pyridinoline (UPYR) and deoxypyridinoline (UdPYR) crosslinks were measured by spectrofluorometry after acid hydrolysis and separation on a reverse phase C18 column by high performance liquid chromatography as reported elsewhere. ${ }^{6}$ The intra-assay and interassay variations were $4 \%$ and $9 \%$ for uPYR and $6 \%$ and $12 \%$ for udPYR, respectively. The excretion of UPYR and udPYR were expressed in ratios of creatinine excretion ( $\mathrm{uPYR} / \mathrm{cr}$ and $\mathrm{udPYR} / \mathrm{cr}$ ) in order to correct for dilution and sampling time. ${ }^{6}$

\section{STATISTICS}

The Wilcoxon non-parametric test for paired differences was used for comparison of the data. The method of Hills and Armitage was used to test for period and carry over effects. ${ }^{7}$ Probability $<0.05$ was considered significant.

The study was approved by the national ethics committee. All children and their parents signed informed consent before entering the study.

\section{Results}

One boy was withdrawn because of a $30 \%$ deterioration of lung function during period 3 (wash-out period). All other children had normal pulmonary function throughout the study. Two boys were excluded from analysis because of compliance was less than $80 \%$. The characteristics of the 13 children who were included in the analysis and the three boys, who were excluded, were similar with regard to age and body surface area. No significant differences in the measured bone and collagen parameters between the run-in period and the wash-out period were found. No carry over and period effect were found. Compliance with the dosage regimen during budesonide treatment was $95 \%(86 \%-104 \%)$, and during beclomethasone dipropionate $96 \%$ (86\%-104\%).

No statistically significant differences in the measured bone and collagen parameters between the run-in period and the wash-out period were found. No carry over and period effects were found

Mean and individual data are shown in figs 1 and 2. The nominal reductions of osteocalcin during treatment with budesonide and beclomethasone dipropionate were not statistically significant. Mean PICP was reduced from 270 to $221 \mu \mathrm{g} / \mathrm{l}(\mathrm{p}=0.03)$, and PIINP from 8.8 to $6.7 \mu \mathrm{g} / \mathrm{l}(\mathrm{p}=0.0002)$ during treatment with budesonide. PICP was reduced from 268 to $215 \mu \mathrm{g} / \mathrm{l}(\mathrm{p}=0.01)$, and PIINP from 8.7 to $5.6 \mu \mathrm{g} / \mathrm{l}(\mathrm{p}=0.0002)$ during treatment with beclomethasone dipropionate. Budesonide treatment reduced mean $\mathrm{UPYR} / \mathrm{cr}$ from 0.25 to $0.21 \mathrm{mmol} / \mathrm{mmol}$ creatinine $(p=0.03)$ and udPYR/cr from 0.037 to $0.029 \mathrm{mmol} / \mathrm{mmol}$ creatinine $(p=0 \cdot 12)$. Beclomethasone dipropionate treatment reduced mean $\mathrm{uPYR} / \mathrm{cr}$ from 0.22 to $0.18 \mathrm{mmol} / \mathrm{mmol}$ creatinine $(p=0.004)$ and $\mathrm{udPYR} / \mathrm{cr}$ from 0.029 to 0.026 $\mathrm{mmol} / \mathrm{mmol}$ creatinine $(\mathrm{p}=0.02)$. The reduction in PIIINP during treatment with beclomethasone dipropionate $(3 \cdot 1 \mu \mathrm{g} / \mathrm{l})$ was more marked than during budesonide treatment $(2 \cdot 1 \mu \mathrm{g} / \mathrm{l})(\mathrm{p}=0 \cdot 001)$.

Figure 3 shows the per cent reduction in the mean value of the measured bone and collagen parameters during budesonide and beclomethasone dipropionate treatment.

\section{Discussion}

Aside from treatment with glucocorticosteroids several factors may influence bone and collagen turnover in asthmatic children such as suppression of physical activity, psychological stress, and severity of the disease. In this short term study of children with mild asthma we tried to keep all variables except glucocorticosteroid treatment constant throughout the study, as we wanted to reduce possible influences of other variables. The finding of similar levels of bone and collagen turnover during the run-in and the wash-out periods separated by four weeks suggested that this was achieved. Studies in 
Figure 1 Individual and mean values of serum osteocalcin, PICP, and PIINP. Column 1: before budesonide treatment; 2 : during budesonide treatment; 3: before beclomethasone

dipropionate treatment; and 4: during beclomethasone dipropionate treatment.
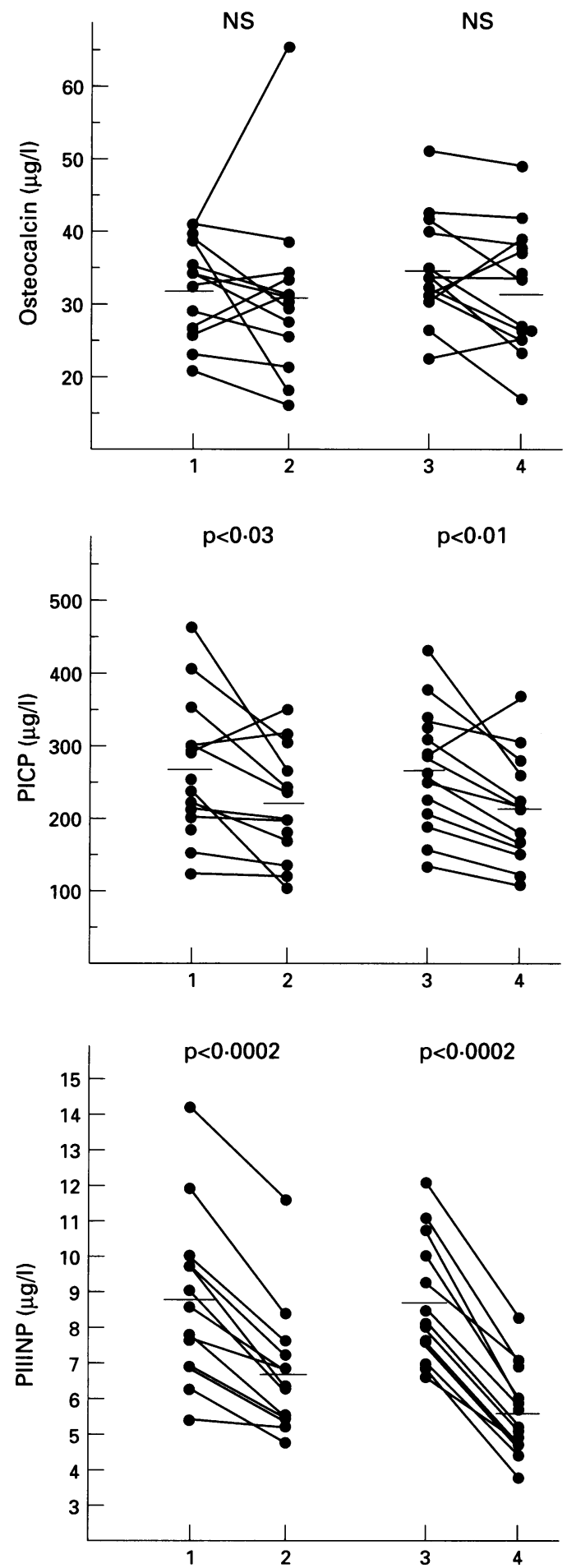

adults have shown that serum concentrations of osteocalcin and PICP and of excretion of uPYR and udPYR crosslinks exhibit circadian rhythms with decreases during the morning, increases in the afternoon, and reaching peak levels during the night. ${ }^{8-10}$ In the present study the possible influence of circadian rhythms was minimised by the time of blood and urine sampling.

Osteocalcin is the most abundant non-collageneous protein of bone. In adults serum concentrations of osteocalcin correlate well with changes in osteoblast activity. ${ }^{11}$ Our findings of no influence on osteocalcin from $800 \mu \mathrm{g}$ dry powder budesonide and beclomethasone dipropionate are in agreement with our previous study of inhaled budesonide in doses of 200-800 $\mu \mathrm{g}$ delivered from a metered dose inhaler. ${ }^{1}$ Contradicting evidence has been found in studies in adults treated with doses of 400-2000 $\mu \mathrm{g}$ beclomethasone and from one study in children treated with $800 \mu \mathrm{g}$ budesonide. ${ }^{1213}$ In the latter study blood samples for analysis were taken after a 12 hour fast in the morning. It is not known to what extent fasting may influence serum concentrations of osteocalcin in children and it must be kept in mind that there is a high interassay difference in osteocalcin measurements. ${ }^{14}$ Furthermore, there are no data on the sensitivity of serum osteocalcin as a marker of osteoblast activity in children. In adults, most of the bone formation occurs as part of a continuous remodelling of bone and only to a limited extent as part of skeletal growth (modelling). In contrast, modelling is the major activity of the skeleton in children, who are increasing bone mass throughout childhood. Serum osteocalcin may be a less sensitive marker of the effect of inhaled glucocorticosteroids on osteoblasts mainly engaged in bone modelling in children.

Type I collagen is the most abundant collagen type in connective tissue and accounts for more than $90 \%$ of the organic matrix of bone. ${ }^{15}$ During the formation of type I collagen PICP is cleaved from the procollagen and released into the circulation. PICP is thus a marker of type I collagen formation. Serum PICP concentrations correlate with bone formation rates measured by histomorphometry
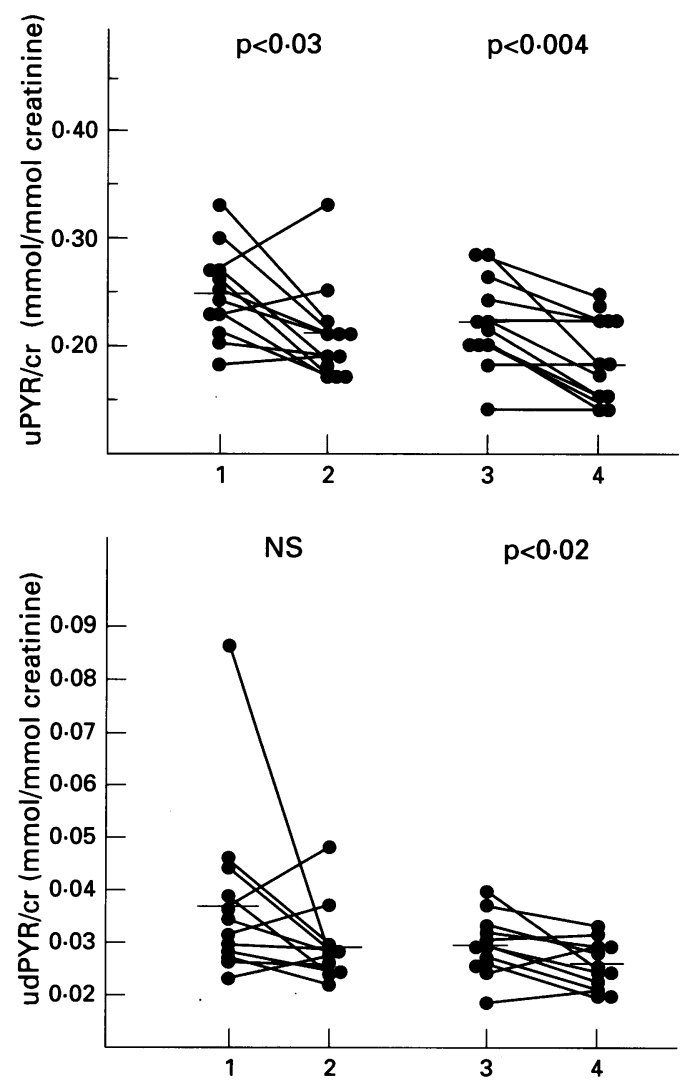

Figure 2 Individual and mean values of $u P Y R / c r$ and udPYR/cr crosslinks. Column 1: before budesonide treatment; 2: during budesonide treatment; 3: before beclomethasone dipropionate treatment; and 4 during beclomethasone dipropionate treatment. 
Figure 3 Mean per cent changes of osteocalcin, PICP, PIIINP, $u P Y R / c r$, and $u d P Y R / c r$ during treatment with budesonide (white columns), and beclomethasone dipropionate (black columns). The statistical differences between budesonide and beclomethasone dipropionate are shown

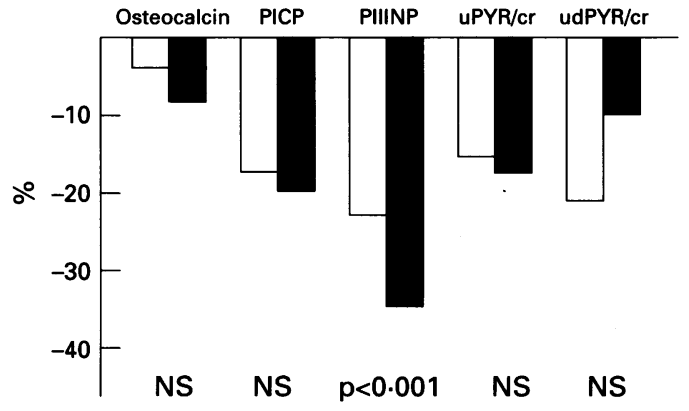

in bone biopsies. ${ }^{16}$ PYR and dPYR are crosslinking amino acids that are formed during maturation of collagen fibrils in bone. PYR and dPYR are released from bone during resorption, and excreted in the urine without undergoing catabolisation. ${ }^{17}$ Though PYR is present in tendon and cartilage it is thought that, due to a slow turnover rate, these tissues contribute only to a little extent to the urinary output of PYR. Thus, the concentration of PYR and APYR in urine are related to the amount of bone resorbed and hence to bone turnover. ${ }^{17} 18$ The simultaneous assessment of PICP and PYR make it possible to estimate the balance between type I collagen formation and degradation. When coupling between the two activities is effective they should be changed into the same direction. The finding of reduced serum concentrations of PICP and reduced concentrations of UPYR and UdPYR during treatment with $800 \mu \mathrm{g}$ inhaled budesonide and beclomethasone dipropionate indicates that the treatments inhibit bone collagen turnover, which may be reset in a suppressed steady state condition. That is in accordance with our previous findings of suppressive effects of oral prednisolone on bone turnover. ${ }^{2}$ PIIINP is released into the circulation when collagen type III, which accounts for $10-50 \%$ of body collagen, is synthesised. ${ }^{19}$ Serum values of PIINP seem to be sensitive markers of collagen synthesis. Furthermore serum PIIINP concentrations correlate with growth rates. 22021 Therefore reduced concentrations of PIINN during both budesonide and beclomethasone treatment may suggest an inhibition of growth.

The present data are in accordance with recent findings of suppressive effect of $800 \mu \mathrm{g}$ inhaled budesonide from a metered dose inhaler on serum concentrations of PIIINP. ${ }^{22}$ However, the suppressive effect of beclomethasone on PIIINP concentrations was more marked than that of budesonide. This suggests that beclomethasone from the Diskhaler may be associated with a greater systemic activity than budesonide from the Turbuhaler. This may be due to variations in systemic bioavailability and systemic potency of the two drugs and administration devices. ${ }^{23}$ A difference in the systemic activity between the two inhaled compounds has been shown in studies of the effect on the hypothalamicpituitary-adrenal axis. ${ }^{24}$

This study indicate that $800 \mu \mathrm{g}$ dry powder inhaled budesonide and beclomethasone dipropionate per day suppress bone and collagen turnover in asthmatic children. The suppressive effect of beclomethasone dipropionate seem to be more marked than that of budesonide. However, long term studies need to be made to clarify the clinical implications of these findings.

We thank the Department of Clinical Chemistry, Esbjerg Central Hospital for technical assistance.

1 Wolthers OD, Riis BJ, Pedersen S. Bone turnover in asthmatic children treated with oral prednisolone or
inhaled budesonide. Pediatr Pulmonol 1993; 16: 341-6.

2 Wolthers OD, Juul A, Hansen M, Muller J, Pedersen S. The insulin-like growth factor axis and collagen turnover during prednisolone treatment. Arch Dis Child 1994; 71: 409-14.

3 Johansen JS, Hansen JEM, Christiansen C. A radioimmunoassay for bone GLA protein (BGP) in human plasma. Acta Endocrinol 1987; 114: 410-6.

4 Pedersen BJ, Bonde M. Purification of human procollagen type I carboxyterminal propeptide cleaved as in vivo from procollagen and used to calibrate a radioimmunoassay of the propeptide. Clin Chem 1994; 40: 811-6.

5 Ristelli J, Neimi S, Trivedi P, Maentausta O, Mowat AP, Ristelli L. Rapid equilibrium radioimmunoassay for the aminoterminal propeptide of human type III procollagen. Clin Chem 1988; 34: 715-8.

6 Schlemmer A, Johansen JS, Pedersen SA, Jørgensen JOL, Hassager C, Christiansen C. The effect of growth hormone (GH) therapy on urinary pyridinoline cross-links in GH-deficient adults. Clin Endocrinol 1991; 35: 471-6.

Hills M, Armitage B. The two-period cross-over clinical trial. Br f Clin Pharmacol 1979; 8: 7-20.

8 Bundberg CM, Markowitz ME, Mizruchi M, Rosen JF. Osteocalcin in human serum: a circadian rhythm. f Clin Endocrinol Metab 1985; 60: 736-9.

9 Hassager C, Risteli J, Risteli L, Jensen S, Christiansen C. Diurnal variation in serum markers of type I collagen syntheses and degradation in healthy premenopausal women. F Bone Mineral Res 1992; 7: 307-11.

10 Schlemmer A, Hassager C, Jensen S, Christiansen C. Marked diurnal variation in urinary excretion of pyridinium crosslinks in preminopausal women. $f$ Clin Endocrinol Metab 1992; 74: 47680.

11 Charles P, Poser JW, Mosekilde L, Jensen FT. Estimation of bone turnover evaluated by 47 -calcium kinetics: efficiency of serum carboxyglutamic acid containing protein, ciency of serum carboxyglutamic acid containing protein, serum alkaline phosphatase and urinary hyd

12 Teelucksingh S, Padfield PL, Tibi L, Gough KJ, Holt PR. Inhaled corticosteroids, bone formation, and osteocalcin. Lancet 1991; 338: 60-1.

13 Sorva $R$, Turpeinen $M$, Juntunen-Backman $K$, Karonen SL, Sorva A. Effects of inhaled budesonide on serum markers of bone metabolism in children with asthma. f Allergy Clin Immunol 1992; 90: 808-15.

14 Masters PW, Jones RG, Purves DA, Cooper EH, Cooney JM. Commercial assays for serum osteocalcin give

15 Melkko J, Niemi S, Risteli L, et al. Radioimmunoassay of the carboxyterminal propeptide of human type I procollagen. Clin Chem 1990; 36: 1328-32.

16 Parfitt AM, Simon LS, Villanueva AR, Krane $M$. Procollagen type I carboxy-terminal extension peptide in serum as a marker of collagen biosynthesis in bone. Correlation with iliac bone formation rates and comparison with total alkaline phosphatase. $\mathcal{f}$ Bone Mineral Res 1987; 2: 427-36.

17 Delmas JD, Schlemmer A, Gineyts E, Riis B, Christiansen C. Urinary excretion of pyridinoline crosslinks correlates with bone turnover measured on iliac crest biopsy in patients with vertebral osteoporosis. $\mathcal{f}$ Bone Mineral Res 1991; 6: 639-44.

18 Branca F, Robins SP, Ferro-Luzzi A, Golden MHN. Bone turnover in malnourished children. Lancet 1992; 340: 1493-6.

19 Prockop DJ, Kivirikko KJI, Tuderman L, et al. The biosynthesis of collagen and its disorders. N Engl f Med 1979; 301: 13-23.

20 Trivedi P, Risteli J, Hindmarsh PC, et al. Serum concentrations of type I and III procollagen propeptides as biochemical markers of growth velocity in healthy infants and children and in children with growth disorders. Pediatr Res 1991; 30: 276-80.

21 Hertel NT, Stoltenberg M, Juul A, et al. Serum concentrations of type I and III procollagen propeptides in healthy children and girls with central precoccious puberty during treatment with gonadotropin-releasing hormone analog and cyproterone acetate. $\mathcal{F}$ Clin Endocrinol Metab 1993; 6: 924-7.

22 Wolthers OD, Juul A, Hansen M, Muller J, Pedersen S. The insulin-like growth factor axis and collagen turnover in asthmatic children treated with inhaled budesonide. Acta Paediatr Scand 1995; 84: 393-7.

23 Johansson SÂ, Andersson KE, Brattsand R, Gruvstad E, Hedner P. Topical and systemic glucocorticoid potencies of budesonide and beclomethasone dipropionate in man. Eur f Clin Pharmacol 1982; 22: 523-9.

24 Pedersen S, Fuglsang G. Urine cortisol excretion in children treated with high doses of inhaled corticosteroids: a comparison of budesonide and beclomethasone. Eur Respir 7 1988; 1: 433-5. 